\title{
Informação estatística: direito à privacidade versus direito à informação ${ }^{1}$
}

\author{
Statistical information: right to privacy \\ versus right to information
}

Nelson de Castro SENRA2

RE S U M O

\footnotetext{
1 Ainda que seja um texto de cunho pessoal, caberá registrar que não teria sido possível realizá-lo sem o convívio privilegiado, primeiro, no Grupo de Trabalho criado com vistas a propor normas e procedimentos destinados à manutenção do sigilo das informações coletadas, produzidas, disseminadas e armazenadas pelo IBGE, nos termos da P.PR. 111, de 19.03.1999, sob a coordenação de Zélia Magalhães Bianchini, (no período de março a dezembro de 1999), e, segundo, no que the decorreu, no Comitê de Sigilo instituído pela P.PR. 894, de 03.10.2002, nos termos da R.CD. 002, de 19.02.2001, sob a presidência de David Wu Tai, que vige ainda. Mas, não thes cabe nenhuma responsabilidade pelas idéias expostas (nem necessária concordância com elas).

2 Docente e Pesquisador, Programa de Mestrado em Estudos Populacionais e Pesquisas Sociais, Escola Nacional de Ciências Estatísticas, Fundação Instituto Brasileiro de Geografia e Estatística. Rua Gal. Canabarro, 706, $2^{\circ}$ andar, Maracanã, 20271-201, Rio de Janeiro, RJ, Brasil.E-mail: <senra@ibge.gov.br>

Recebido em 30/9/2004 e aceito para publicação em 26/11/2004.
} 
A B S T R A C T

The demand for statistics is rising now-a-days. Statistics about everything are being demanded, as an essential and specific information to generate knowledge of complex realities, in a globalized world, where there is an intense competition (and perhaps cooperation too). But, due to the special nature of statistics (the manner in which they have to be produced), the right to information of all, will deny to many the right of privacy. In fact, to produce statistics is essential to convince (or to oblige) each informant, to brake his/her privacy, revealing selected aspects of someone'st individuality. To convince someone to cooperate, he/she receives from statistical agencies the promise to limit the use of his/her individual information, which will never be disclosed individually, being used only in statistical aggregations. As a consequence, the statistical agencies' capacity to disseminate information is limited, so being also restricted the people's right to information. The aim of this text is to analyze that dilemma, through the study of obligation and its other face, the confidentiality. This study resulted, once more, of intellectual investigations made long ago by the author.

Key words: statistics, privacy, secrecy, professional deontology, administrative register, statistical register, research program.

\section{N T R O D U Ç Ã O}

Entre os direitos humanos consagrados e universalizados, valerá realçar o direito à privacidade (ao particular, à intimidade, ao silêncio) e o direito à informação (para desenvolver conhecimentos, na pesquisa diária da verdade). Sem informação, não existe conhecimento, e sem conhecimento não existem condições para que o sujeito se insira e avance, num mundo que concorre o tempo todo. Mais que estar, apenas estar, no mundo dos negócios e das relações sociais, é preciso inovar nele, e para isso é imperativo haver conhecimento, o que depende de informação. O direito à informação torna-se, mais e mais, um direito básico, um direito de cidadania.

Nesse contexto, para exercer o direito à informação, quem demanda as estatísticas, as quer a tempo, e nos formatos idealizados. Mas, nem toda informação estatística demandada pode ser oferecida, na conta do respeito à privacidade dos que forneceram as informações individuais necessárias à sua elaboração. De fato, aos informantes garante-se sigilo, reserva, limites no uso das informações individuais prestadas, adstritas à elaboração das estatísticas, em cujo processo produtivo as individualidades são superadas ao serem agregadas em sucessão, até se tornarem as estatísticas. Essa reserva oferecida aos informantes individuais é imperativa, sob pena de virem a ignorar as demandas por informações individuais feitas pelas instituições estatísticas, ou de se negarem à revelação de aspectos seletivos de suas individualidades. O direito à privacidade é um direito inegável aos cidadãos.

Pois neste texto, antes que centrar atenção nos seus aspectos técnico e tecnológico (CITTEUR; WILLENBORG, 1993; FEDERAL STATISTICAL..., 1978; 1994; DOYLE et. al., 2001) realçam-se seus aspectos filosófico e histórico (SILVA, 1988; BIANCHINI, 1995; SENRA, 1996; SENRA 1999). Pretende-se recuperar, primeiro, o significado da obrigação na prestação das informações individuais para fins estatísticos; segundo, o significado da garantia do sigilo (reserva, segredo, confidencialidade) às informações individuais prestadas (sendo verso e reverso da mesma moeda); terceiro, suas trajetórias no contexto das instituições estatísticas, marcando os desafios 
futuros, em boa medida já presentes. Entendendo-se obrigação e sigilo, chega-se à análise dos direitos à privacidade e à informação.

\section{Quebra voluntária de privacidade}

Toda quebra de privacidade, revelando aspectos seletivos das individualidades, mesmo quando realizada voluntariamente, pressupõe declaração explícita de limites de uso, implicando reserva ou sigilo. Vejamos alguns casos.

Por razões pessoais, para ganho pessoal, pessoa alguma reluta em revelar sua privacidade, sua mais recôndita intimidade. Assim será, por exemplo, diante do médico, num consultório; nesse caso, ninguém deixará de informar se é cardíaco, se é diabético, enfim, se porta alguma doença; de fato, se incorrer no silêncio, na reserva, poderá colocar em risco sua vida. Também assim o é diante do advogado (em causas penais ou cíveis), do sacerdote (em busca do perdão dos pecados, na intenção da salvação), do psicanalista (no arranjo do coração e/ou da mente; ou seria da alma?), entre outros profissionais assemelhados ${ }^{3}$.

Diante desses profissionais, cujas atuações centram-se e concentram-se nas individualidades, a abertura do indivíduo é voluntária e expontânea, sem nenhuma imposição, pautandose no interesse pessoal. Mas, sempre restam riscos de vazamento, pois a intimidade dos indivíduos passa, agora, a estar compartilhada, vale dizer, passa a estar, ao menos nas mentes, se não também nas anotações (nos registros, nos arquivos) do médico, do advogado, do psicanalista, do sacerdote. Por essa razão, ficam temores legítimos: e se houver revelação, divulgação, seja em ambientes reservados, seja em ambientes públicos? Vale a pena correr riscos? Vale bancar eventuais prejuízos advindos? Diante disso, algo além do interesse precisa ocorrer, trazendo tranqüilidade, e isso virá na forma de confiança no profissional, não numa confiança personalista, ainda que isso pese, mas numa confiança estrutural nas profissões, conformado nas respectivas deontologias, sob rigoroso controle das corporações.

Em outras ocasiões, diferentes, também ocorrem revelações voluntárias de intimidade pelos indivíduos. Por exemplo, nas escolas, nos hospitais, entre outros lugares, quando ao fazer-se os registros de ingresso, interessa ao indivíduo revelar abertamente sua intimidade, sob pena de, depois, no caso da escola, receber um diploma errado no seu nome, na sua idade, na sua filiação, ou, no caso do hospital, receber uma medicação inadequada, levando-o à invalidez ou mesmo à morte; e assim em diante. Também será o caso dos seguros, onde a falsidade, quando detectada, implicará na negação posterior do reembolso pela seguradora; será o caso também das relações bancárias, creditícias, comerciais; entre outras várias.

Nessas situações, várias pessoas (não uma apenas, como o advogado, o médico, em ambientes reservados) terão acesso aos registros contendo as revelações individuais, pessoas cujas profissões não agregam inequívocas configurações deontológicas, não sendo disciplinadas por corporações controladoras, disso, então, decorrendo fundados temores. Então, a necessária confiança decorrerá das organizações que abrigam aquelas pessoas, e a elas caberá oferecer as devidas garantias de reservas aos registros realizados. Contudo, nem sempre o fazem de forma clara, explícita, seja por simples descuido (ou por ignorância da natureza dos registros individuais), seja por máfé, com vistas a, por exemplo, venderem cadastros individuais para fins comerciais (se tal, comprovada a utilização imprópria dos registros,

\footnotetext{
${ }^{3}$ É o caso, mutatis mutandis, dos jornalistas, diante de suas fontes. E o é também, com as devidas nuanças, das famosas cortesãs, em seus salões e em seus ninhos de amor, tradicionalmente fidelíssimas em suas atividades, diante de seus clientes, como bem conta a história.
} 
restará ao indivíduo socorrer-se aos tribunais). Como seja, mesmo sob esses riscos, naqueles casos o indivíduo há de se revelar sem restrições, sob pena de se ficar alijado dessas relações sociais tão vitais e comuns.

\section{Quebra obrigatória de privacidade}

Quando não emerge imediata vantagem, para levar-se os indivíduos a quebrarem suas individualidades, revelando aspectos seletivos das suas individualidades, será preciso mais que declarar de modo explícito os limites de uso, garantindo reserva ou sigilo. Por certo, será preciso constranger os indivíduos, para demovê-los de se negarem a revelar-se ou fazerem isso com delongas e/ou desatenção.

É o caso, por exemplo, da declaração de rendas e de bens feita ao órgão da Receita Federal. Ora, não fazer a declaração, perdendo o registro como pessoa física ou como pessoa jurídica, significa ser marginalizado nas transações comerciais, bancárias, dentre várias outras. Além desse prejuízo, se a declaração contiver falsidade, detectáveis nos programas de controle, significa punição, na forma de cobranças financeiras (em certos países, pessoas são levadas mesmo às prisões). É o caso, também, do registro de serviço militar (para os homens; em alguns países, para homens e mulheres), do registro eleitoral (para todos os votantes), entre outros; não tê-los ou perdê-los, ainda mais falseá-los, implica punição e prejuízo (tolhendo e limitando as relações sociais) ${ }^{4}$.

Pois, nesses casos, está-se diante das antigas e famosas inscrições dos estados (com "e" minúsculo) para efeito da conformação e do funcionamento dos Estados (com "E" maiúsculo); aí estão os registros da condição civil, os registros alfandegários, os registros de propriedades (por exemplo, os de terras), enfim, registros diversos de interesse prioritário dos Estados que os pensam e obrigam suas realizações. Mas, com o tempo, os Estados assumem que não podem (não devem) ignorar seus cidadãos, cabendo-lhes, antes, protegê-los, melhor, respeitar-Ihes (estimular-Ihes) as liberdades. Então, para além da punição aplicada aos resistentes e recalcitrantes, sempre prevista nos registros, passam a associar-lhes, cada vez com mais clareza, limites às suas utilizações; ao mesmo tempo, procuram conquistar os informantes, tentando convencê-los dos ganhos que auferem em meio aos ganhos coletivos. Diferente das organizações, que nem sempre oferecem garantias explícitas de limites (de reserva, de sigilo), as instituições envolvidas (públicas e oficiais) o fazem, claramente, zelando pela competência de seus funcionários.

Esses registros individuais, declarados por obrigação, têm fins administrativos; vale dizer, destinam-se à administração, e aí, e em nada mais, reside sua função. Para tanto, têm e terão caráter individual, porquanto interessam-se pelos indivíduos. Contudo, se útil para administrar as respectivas atividades, pode-se promover agregações; por exemplo, no caso do órgão da Receita Federal: quantos contribuintes entregaram a declaração nos prazos, quantos pagaram, quantos tiveram devolução, quantos tiveram isenção, e assim em diante. Nesse caso, não se tem estatísticas propriamente, mas antes o que podemos denominar de quase-estatísticas, como meras contagens; como seja, se feitas pelos órgãos gestores dos registros, então o sigilo associado estará respeitado; mas, se feitas por outros órgãos, digamos pelas instituições estatísticas, então será preciso discutir a difícil questão da delegação do sigilo.

Indo mais fundo, sendo possível delegar-se o sigilo a outros órgãos, estatísticas

\footnotetext{
${ }^{4}$ É claro que em algumas dessas situações, o indivíduo pode extrair prazer, como, no caso das eleições, ao ver seu candidato eleito. Noutras, mormente naquelas associadas ao pagamento de tributos, não há como extrair prazer (a menos que se tenha muita visão social, muito sentido do coletivo).
} 
(verdadeiras estatísticas) poderão ser geradas, aproveitando-se as informações individuais existentes naqueles registros. Isso foi feito muito, ao longo dos tempos, e, embora em diminuta dimensão, continua sendo feito. Contudo, mais e mais, nas quatro ou cinco últimas décadas, foram sendo criados registros específicos para fins estatísticos, os chamados registros estatísticos, resultantes de pesquisas por amostra ou por censo. Para tanto, por interesse do Estado, que se quer revelado em números, os indivíduos são chamados a quebrarem suas privacidades e, logo ficará evidente, não o fazem voluntariamente, senão obrigatoriamente, para o que Ihes será dada a garantia de sigilo, e se Ihes imporá punição, caso neguem, atrasem ou falseiem as informações.

\section{A natureza das estatísticas}

As estatísticas são expressões numéricas de coletividades; as coletividades que elas expressam numericamente são previamente organizadas, o que quer dizer que as estatísticas são construções. As estatísticas importam, sobretudo, à formulação, ao controle e à gestão das políticas públicas, e também, às suas avaliações, e, por conseqüência, ao acompanhamento da competência dos governantes (SENRA, 2001;2002).

Dito doutra forma, as estatísticas tornam próximos mundos distantes, tornam presentes mundos ausentes, fazem-nos conhecidos e, portanto, pensáveis. Pelas estatísticas, toda uma população, uma economia, uma sociedade, um território, em alguns aspectos seletivos, são postas diante dos decisores, sobre suas mesas, na forma de tabelas, de gráficos, de cartogramas. Os mundos, reduzidos nos processos de captação, ficam, após as comparações e as combinações, ampliados; sabe-se, então, o que não se sabia, e sabe-se, agora, muito mais, com distinta profundidade. Dessa forma, as estatísticas configuram tecnologias de distância, servindo à maravilha como tecnologias de governo. Assim sendo, as estatísticas, além de formas de saber, são fonte de poder.

As estatísticas são construções, não quaisquer construções, ao sabor dos ventos, das vontades; são construções amparadas nas ciências (conceitos, definições) e em métodos de pesquisa consagrados. As estatísticas, embora expressem coletividades, partem de registros individuais ${ }^{5}$, que, no processo de agregação, são superados. Sim, parte-se de inscrições de primeira ordem, e passa-se a sucessivas inscrições agregadas de segunda, de terceira, de quarta, enfim, de enésima ordem, a ordem última das estatísticas. Dessa forma, as estatísticas falam do todo e não das partes, só retornando às individualidades indiretamente, através das políticas públicas.

Por esse processo, dá-se ordem à desordem, dá-se forma ao informe, reduzem-se as diferenças, as heterogeneidades, as multiplicidades, sempre confusas, difíceis de se governar. Superam-se as individualidades e configuram-se as individualizações (individualidades individualizadas), fazendo cada um ver-se no outro, no coletivo configurado numericamente; por exemplo, dada uma medida de inflação, de produto, de renda, ou outra, de pronto nos comparamos, e nos vemos acima ou abaixo da média, da mediana, como esteja expressa a medida. Configurando coletividades (individualidades individualizadas), as estatísticas permitem a formulação das políticas públicas, seus controles e avaliações, viabilizando o controle cidadão aos governantes pelos governados. Por isso, as estatísticas interessam muitíssimo.

As estatísticas, tenha-se clareza, são informações desde o início, porquanto impregnadas de significação já na fundação, donde, qualquer utilização ou reutilização, para ser bem

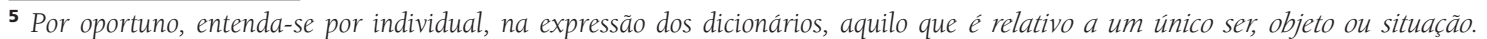


feita, exigirá a compreensão das suas limitações de fundação. Dito de outra forma, mais que signos numéricos, estando no plano da sintática, as estatísticas, por terem significados já na fundação, figuram também no plano da semântica. Definitivamente, as estatísticas são informações já ao tempo das emissões, pelas instituições estatísticas, e sendo assim, imporá aos receptores limitações na re-significação. As estatísticas podem muito, não tudo, entretanto.

\section{Estatísticas via registros administrativos}

Por muito tempo, a elaboração das estatísticas fundou-se nas informações individuais existentes nos (antigos) registros administrativos.

Os registros com finalidade administrativa eram abundantes, criados na esteira da formação dos Estados Nacionais; inscreviam os estados, para efeito de se inscreverem; o exemplo mais acabado são os registros ditos civis (nascimento, falecimento, casamento), devidamente laicizados. Mesmo os antigos censos tinham um caráter de registro administrativo, inscrevendo as famílias, seus membros e seus bens, para efeito de tributação e de recrutamento.

Diante dos Estados Nacionais, crescentemente poderosos, tendo a posse legítima da violência, as informações eram prestadas e os registros elaborados, tudo de modo obrigatório, sem tergiversações. Vencidos os primeiros instantes, pouco a pouco, os indivíduos perceberam a importância de estarem inscritos, tornandose cidadãos, daí, passando a revelar-se voluntária e corretamente, vendo surgir alguns registros específicos (de novo, o melhor exemplo, é a laicização dos registros ditos civis).

Registros em profusão são pensados e impostos. Deles derivam-se as estatísticas, os números de interesse dos Estados, sobre as populações, em sociedade, num território. Ao longo do século XIX, as estatísticas ganham visibilidade, na esteira, não mais da criação dos Estados Nacionais, mas sim da sua sofisticação instrumental, que, mais e mais, se quer racional, no amparo das ciências. Os mundos distantes e ausentes, tornando-os próximos e presentes, os saberes dos mundos permitem pensá-los e, em sucessão, governá-los, dominá-los, controlá-los, em suma, exercer poder sobre eles.

Por muito tempo, será realçada sua natureza administrativa, seu caráter contábil. Virão as enquetes, tão caras a Colbert, ao tempo de Luís XIV, algo como censos nacionais com conteúdos limitados; virão, depois, as sondagens, tão caras a Le Play, ao tempo do Napoleão III, algo como censos locais com intensos conteúdos. Tradicionais ou inovadores, aos registros se associava a potência dos Estados, sendo atendidos pelos indivíduos por obrigação, e, por isso mesmo, nada se dizia dos limites nos seus usos. Isso só se dará ao longo do século XIX.

Estatísticas são elaboradas; estatísticas administrativas. Os técnicos envolvidos, geralmente servidores públicos, dada a razão inicial desses registros, agiam com zelo, algo que podia levar à noção de ética. Pois a idéia de zelo está posta nos debates dos Congressos Internacionais de Estatística, havidos no século XIX, em suas nove reuniões plenárias, sobretudo na sétima delas, havida em Haia, em 1869, quando se advoga que aos governos competiria promover a capacitação e assegurar o extremo zelo dos empregados das instituições nacionais de estatística, cujas criações e existências são, então, defendidas e definidas no escopo.

Há dois caminhos à derivação das estatísticas (estatísticas verdadeiras não apenas quase-estatísticas) utilizando os registros administrativos. Primeiro, fazendo-o através dos profissionais responsáveis pelos referidos registros, quando, então, o sigilo não estará sendo aberto a olhares estranhos. Segundo, fazendo-o através de outros profissionais, em outros órgãos, longe da origem daqueles 
registros, quando, então, o sigilo estará sendo aberto a olhares estranhos, e sua delegação deverá ser tratada. No primeiro caminho, estar-se-á cometendo aos profissionais responsáveis uma tarefa adicional, além de nova, talvez difícil de ser posta na rotina, e de ser assimilada. No segundo caminho, a cessão dos registros, abrindo-os a olhares outros, deverá revestir-se de extremo cuidado, tendo-se que confiar na instituição estatística responsável. Ora, tendo em vista que nas instituições estatísticas o sigilo é tratado zelosamente, formando sua natureza, será tranqüila e pacífica essa delegação; de todo modo, por se estar passando de uma instituição a outra, há de se dar atenção à questão.

\section{Estatísticas via registros estatísticos}

Com o passar do tempo, chegando à segunda metade do século $X X$, as instituições estatísticas, nacionais, públicas e oficiais, se consolidam e se transformam em instituições de pesquisa, tendo caráter científico.

A demanda cresce, em resposta ao planejamento nacional, de um lado, e, de outro, a oferta pode agora crescer, como nunca, com a criação dos registros estatísticos, através das pesquisas amostrais; ademais, a oferta se estrutura fortemente através da contabilidade nacional, que também a articula com a demanda (num papel intrínseco de coordenação). Os registros estatísticos, sob métodos refinados e rigorosos, ganham a cena; já os registros administrativos, perdem o estrelato, retirando-se aos bastidores.

As realidades complexas, a serem percebidas e apreendidas, supõem melhores estatísticas; as instituições estatísticas precisam de melhores profissionais, melhores e com diferentes formações: Economistas, Sociólogos,
Demógrafos, entre outros. Até então ausentes das instituições estatísticas, passam a atuar par a par com os Estatísticos que, ainda que quase sempre presentes, com as técnicas amostrais exigidas, melhoram suas qualificações. Assim, pouco a pouco, conforma-se um profissional especializado na elaboração das estatísticas, a que chamaremos de Estaticistas.

Mas, mesmo a crescente visibilidade e importância das estatísticas, digamos, nos melhores momentos da economia keynesiana, com os estados provedores, para além de protetores, (quase) nunca foi possível conquistar a voluntariedade dos informantes na geração dos registros estatísticos. Impôs-se, aqui e alhures, imputar-lhes obrigação, sob garantia de sigilo, natural na superação intrínseca das individualidades, no processo de pesquisa. Além do sigilo, definiu-se uma punição através de multas. Tudo isso através de texto legal: obrigação, sigilo e multa.

Aqueles instantes, em que os indivíduos são chamados a participar, quebrando suas privacidades, serão instantes de completo aborrecimento, com a terrível sensação de perda de tempo. De um lado, por não se sentirem diretamente beneficiados pelas estatísticas, às vezes, por se sentirem prejudicados ${ }^{6}$. De outro lado, por não se sentirem partícipes da produção das estatísticas, seja por ignorância do seu processo produtivo (de fato, de difícil percepção), seja pelo longo tempo que decorrerá até a divulgação das estatísticas, que lhe é dito, resultarão das informações individuais prestadas, sem contar que (em tese) ao serem divulgadas, dada sua natureza, não lhes serão associados diretamente. E se fecha o ciclo completo de incompreensão; revelar-se, quebrando privacidade para fins estatísticos é, de fato, aos informantes, um transtorno, um aborrecimento,

\footnotetext{
$\overline{6}$ Às vezes, o sentimento de prejuízo decorre de uma má interpretação do significado das estatísticas (por exemplo, querê-las referidas a espaço diverso daquele que contém; associá-las a condições pessoais, às quais jamais se referem; levar-lhes, para comparação, intuição pessoal; e aí em diante), outras vezes, esse sentimento decorre dos usos oficiais que se dá às estatísticas, nem sempre os mais isentos e "justos". De todo modo, fica o sentimento de desconforto, de insatisfação.
} 
e só o farão se estiverem sujeitos a alguma punição. Mas, que punição seria efetiva? Multa em valor? Que valor? Como cobrar? Etc.

Não obstante as dificuldades, os registros individuais levantados para fins estatísticos são tornados legalmente obrigatórios e sua não prestação, com veracidade, é passível de punição através de multas, sem prejuízo da obrigação, que permanece. Mas, para além das dificuldades operacionais de aplicação das multas, sua aplicação não garante a veracidade das informações que lhe devem decorrer; pelo contrário, as colocam sob suspeição (sem contar que, dada a burocracia envolvida, provavelmente as informações só serão prestadas depois de vencidos os prazos da pesquisa específica, tornando-se, então, inúteis). A punição poderia atuar como efeito demonstração, não para atender àquela pesquisa específica, que não poderia ficar esperando, mas antes para inibir recusas em futuras pesquisas; contudo, os informantes variam entre pesquisas, podendo nunca haver coincidência, nem de pessoa, diretamente, nem de outras pessoas na proximidade, e, de novo, poderá não ser efetiva a punição.

Então, diante disso tudo, no momento da entrevista, em lugar de dobrar os informantes pela imposição de obrigação, com a ameaça da punição da multa, procura-se suavizar a situação, realçando a garantia de sigilo com que a lei protege as informações individuais prestadas, e que, ademais, é natural no processo produtivo das estatísticas, por sua natureza agregada, referida a coletivos. A obrigação é deixada em repouso, sem aplicação da punição; tenta-se convencer o informante à participação, garantindo-Ihe rigoroso sigilo. Ora, dar aos informantes individuais garantia de sigilo, não é tarefa difícil, pois que, como visto, na natureza do processo produtivo das estatísticas, embora as individualidades sejam a origem de tudo, elas se perdem na agregação, passando a falar do todo, do agregado.

Espera-se tranqüilizar o informante, levando-o a revelar sua individualidade, vale dizer, abrir-se fielmente, verazmente, em sua privacidade, sem risco de vê-la ou tê-la divulgada ${ }^{7}$. Contudo, não se consegue fazê-lo esquecer que todo o dito permanece registrado, nalgum lugar; ou seja, superar as individualidades no processo produtivo das estatísticas, não é apagá-las, e se as mantém para ulteriores utilizações (com fins estatísticos, naturalmente). Por isso, a credibilidade da instituição estatística responsável importa muitíssimo; seu bom nome é vital.

E, de fato, as instituições estatísticas não medem esforços para dar efetividade à garantia de sigilo, não deixando em hipótese alguma que as informações individuais tenham outro uso que não os fins estatísticos. Empenham-se, verdadeiramente, com vista a tornarem eficientes e eficazes suas ações, na garantia do sigilo. Mas, como sempre, a eficiência é invisível, ao passo que a ineficiência, por eventual e rara que seja, aparece sempre muito rápido. Portanto, uma espada de Dâmocles paira sempre sobre as cabeças dos envolvidos, nas instituições estatísticas; e todo cuidado é pequeno.

Pois, dada a garantia de sigilo, as instituições estatísticas sempre se empenharam em torná-la efetiva, não medindo esforços no avanço de métodos; de fato, todas as etapas do processo de pesquisa foram sendo objeto de atenção, para que o sigilo jamais fosse quebrado. Além dos métodos e das técnicas, invoca-se seu respeito como ética, pondo-a na deontologia dos

\footnotetext{
7 Mas, diante do discurso do sigilo, o informante poderá pensar: "se minha informação individual se perde no todo, então, posso me relaxar e informar com ressalvas, com reservas, não exatamente com falsidade; sei que não estou sendo correto, mas, de todo modo, estou participando, não estou recusando informação; apenas estou sendo precavido, afinal um homem prevenido vale por dois, e mais vale prevenir do que ter que remediar; durmo tranqüilo, sem dramas de consciência". Se for assim, se fosse assim, seria perverso; e, é claro, espera-se o contrário.
} 
Estaticistas. Por todos os meios, empenha-se para tornar eficazes as ações em favor do sigilo garantido ao informante; a eficiência é invisível, enquanto que a ineficiência, por passageira e eventual que seja, aparece sempre muito rápido; por isso, todo cuidado é ainda pouco.

\section{Atender e garantir o sigilo}

Dessa forma, para evitar riscos de quebra do sigilo, o ideal será sempre divulgar o mínimo na máxima agregação. Eis a ideal oferta padrão: poucas tabelas, bastante agregadas, contendo um enfoque específico à compreensão das realidades complexas, o enfoque das instituições estatísticas. Pouco a pouco, contudo, isso deixa de atender aos estudiosos e aos pesquisadores, mais e mais numerosos, querendo produzir suas agregações peculiares, com seus próprios enfoques. Tabelas outras, fora as padrões, que não satisfazem, são demandadas; isso preocupa as instituições estatísticas.

Postas na forma de papel, era muito difícil atender às informações. Com o passar do tempo, foram postas em arquivos eletrônicos, o que facilitou as releituras. Contudo, as tecnologias existentes, sempre de grande porte, só eram disponíveis às instituições estatísticas, o que impunha limitações às demandas expressas. Precisava-se da intermediação dos profissionais das instituições estatísticas, incapazes de atender aos muitos pedidos; apenas alguns poucos ficavam satisfeitos, ao fim e ao cabo de muitas negociações, e longas demoras. Houve então intenso descontentamento com as instituições estatísticas.

Contudo, no seguir do tempo, a tecnologia de processamento se sofisticou e, sobretudo, simplificou-se. Agora, um computador pessoal, minimamente potente, é bem capaz de fazer operações volumosas em tempos viáveis. Já não se está sujeito às restrições das máquinas enormes; todos se sentem capazes de operar arquivos eletrônicos com as informações individuais. Mas, deixar que pessoas estranhas as manuseiem significa agredir o sigilo, o que não é aceitável. Além disso, os arquivos eletrônicos existentes nas instituições estatísticas não estavam preparados para manipulação em microcomputadores; isso, contudo, logo será resolvido na razão da assimilação dos microcomputadores pelas próprias instituições estatísticas. Não obstante, ficava a questão do sigilo, não sendo, em princípio, admissível deixar que pessoas estranhas acessassem as informações individuais registradas pelas instituições estatísticas.

Cresce a pressão, e uma solução torna-se inadiável; é quando decidem divulgar os chamados microdados, com a devida reserva do sigilo. O que são os microdados? Em linhas gerais, são informações individuais sem identificação dos indivíduos, portanto, com a perfeita reserva do sigilo. Isso é quase sempre possível, em diferentes pesquisas, nas sociais em especial, e quando não o é, especialmente nas econômicas, faz-se alguma agregação, ainda que menor do que as usuais. De fato, nas pesquisas sociais em geral pode-se revelar algo muito próximo da informação individual, sem os riscos de revelação; já no caso das pesquisas econômicas, a situação é bastante diferente, uma vez que divulgá-las pode levar à revelação dos informantes (nesses casos, muitas vezes, nem agregações são possíveis). De todo modo, há um grande avanço.

Alguns acessam os microdados e se satisfazem; são capazes de compreendê-los e de manipulá-los. Outros, não poucos, não são capazes de entendê-los, nem manuseá-los. Então, pedem socorro às instituições estatísticas que não conseguem responder na rapidez desejada, ainda menos na intensidade. Logo virá a saída na forma da criação de sistemas de acesso e de análise (extração) dos microdados, facilitando a elaboração de tabelas, gráficos e 
cartogramas, em agregações específicas ${ }^{8}$. Mesmo esses sistemas, sem dúvida amigáveis, não são de uso fácil a pessoas pouco afeitas aos avanços da informática (sem olvidar a dificuldade de entendimento das estatísticas). Então, de novo, pede-se socorro às instituições estatísticas que, sabendo utilizar aqueles sistemas, conseguem rapidamente prestar atendimento. E a situação melhora muito.

Contudo, em que pesem os avanços, os microdados não atendem a algumas pessoas, em particular aos estudiosos refinados e exigentes, bem assim, às instituições estatísticas congêneres, atuantes num eventual sistema estatístico. Para seus estudos e análises precisam acessar as informações individuais; na verdade não querem as mesmas, mas precisam passar por elas. É o caso, digamos, dos estudos longitudinais: 0 ajuste dos modelos precisa das informações individuais, para apenas passar por elas. São muitas as pressões por essa liberação, cabendo sopesar a questão do sigilo. Duas formas de solução emergem. Uma, através do acesso a informações identificadas, em salas públicas restritas; pessoas, distintamente qualificadas e associadas a instituições consagradas, geralmente instituições públicas de pesquisa, submetem seus projetos à avaliação das instituições estatísticas que, se os aprovam, liberam o acesso às salas; feito o manuseio, depois da avaliação das instituições estatísticas, liberam-se as agregações realizadas. Outra, consiste na liberação das informações individuais, postas no ambiente de trabalho de instituições específicas, quando então o sigilo estaria delegado; isso se faz, quando se faz, com extrema relutância e parcimônia, sob intensa polêmica; é o caso de atender a parceiros, digamos, instituições estatísticas congêneres.

Enfim, os institutos de estatísticas, que precisam da obrigação, não há dúvida, agem no papel da corporação profissional controladora. Fica-se, a todo instante do processo produtivo das estatísticas, com a responsabilidade de cumprimento rigoroso da garantia de sigilo oferecida aos informantes. A garantia dada antes, ao informante, na forma de discurso, deverá, depois, ao longo do processo produtivo das estatísticas, conformar métodos estritos, não sendo possível e aceitável qualquer risco de quebra da mesma. Tanta atenção, contudo, ao fim e ao cabo, poderá conduzir à negação do direito à informação.Vale dizer, em nome do sigilo, para não arriscar-se, restringe-se a disponibilidade de estatísticas ao mínimo, ou seja, trabalha-se na agregação máxima (temática e espacial, quiçá também temporal). Mas, se de um lado o zelo com o sigilo atende à credibilidade da instituição estatística, de outro lado, as eventuais restrições decorrentes ameaça-lhe a legitimidade; tem-se, então, um dilema embaraçoso.

Em suma, não resta dúvida que as instituições estatísticas vivem numa corda bamba: de um lado, zelam extremadamente por sua credibilidade (posta de dentro para fora), e o fazem limitando a divulgação das estatísticas. Não sendo possível limitar-se ao conjunto mínimo de tabelas, que tradicionalmente disponibilizam como acesso padrão, acabam criando condições para crescentes auto-atendimentos (já que não conseguem materializar atendimentos personalizados), na forma de microdados (com informações individuais não identificadas); ademais, criam também especiais condições de acesso a informações individuais identificadas, com restrições e reservas extremas. De outro lado, tanto menos oferecem, por razões de credibilidade, tanto mais ferem sua legitimidade (dada de fora para dentro), faces da mesma moeda, a moeda da existência das instituições estatísticas. Há aí um imenso imbróglio, a exigir

\footnotetext{
8 O Instituto Brasileiro de Geografia e Estatística (IBGE) acaba de criar e dispor do Banco Multidimensional de Estatísticas (BME), de grande sucesso, sendo usado através de assinatura. Por demais, o uso intenso da Internet, promove uma abertura essencial ao auto-atendimento.
} 
reflexão contínua e precisando de tratamento conjunto.

\section{Fazendo uma síntese}

As instituições estatísticas empenham-se em garantir o sigilo; nenhuma torneira poderá vazar. O menor descuido poderá fazer ruir o edifício da obrigação, que é vital. De fato, sem as informações individuais não há estatísticas. Mesmo que se intensifique o movimento de revalorização dos registros administrativos como fonte de informações individuais para fins de geração das estatísticas, os registros estatísticos seguirão importantes; como não são voluntários, é essencial que a obrigação que lhes é associada seja, o mais possível, pacificamente cumprida e aceita, para que gerem informações fidelíssimas (informações individuais duvidosas seriam mortais para a qualidade das estatísticas). Precisa-se da obrigação, como fator de existência e de sobrevivência, e, como parte de sua sustentação, afiança-se o rigoroso sigilo, cujo cumprimento se dá, idealmente, restringindo-se à agregação máxima a divulgação das estatísticas.

Contudo, a demanda de informação estatística cresce a cada dia, numa natural manifestação da sociedade da informação; quer-se informação, para dela derivar-se conhecimento. Pois, dentre todas as informações desejadas e desejáveis, as informações estatísticas são (e sempre foram) da maior relevância, sobremodo por sua promessa de objetividade. Dessa forma, a tendência de oferecer-se o mínimo na máxima agregação, torna-se gradualmente insustentável. Negar o direito à informação é, por parte das instituições estatísticas, restringir sua legitimação, do que decorre que, de algum forma, elas terão que dosar seu respeito extremo ao direito à privacidade, na forma de garantia ao sigilo, no estrito uso das informações individuais a elas prestadas (por obrigação). Vive-se esse dilema: nenhum dos dois direitos, seja o da privacidade, seja o da informação, pode ser negado, mas ambos podem ser, em alguns momentos, antagônicos e conflitantes.

É nesse contexto que as instituições estatísticas foram avançando na diminuição da máxima agregação, antes expressa nos planos tabulares, aqueles que configuravam o atendimento padronizado. Nesse movimento foram surgindo os microdados, com informações individuais sem identificação dos informantes, portanto, no respeito estrito ao sigilo. Permitem a geração de novos planos tabulares, vale dizer, permitem diferentes enfoques analíticos, variando de pessoa para pessoa, diferentes daqueles enfoques adotados pelas instituições estatísticas. As próprias instituições estatísticas os utilizam para ampliar e acelerar seus atendimentos (mais ou menos personalizados).

Mas, aberta a torneira da informação, aumenta sua demanda. Os microdados ajudam muito, mas seu manuseio não é nada simples e imediato. Então, as instituições estatísticas cuidaram de avançar na criação de sistemas de acesso, aumentando o caráter amigável do processo. Nessa situação, mesmo que tais sistemas sigam sendo difíceis para muitas pessoas, servem às instituições estatísticas que, então, agilizam seus atendimentos, ampliando a satisfação dos demandantes, e, em decorrência, aumentando sua legitimidade (sem perda da sua credibilidade).

Contudo, mesmo com os microdados, um avanço inegável, sobretudo quando associados aos sistemas de acesso, muitos continuam insatisfeitos, querendo e precisando ter acesso às próprias informações individuais para fazerem suas análises. Isso será feito através de extrema segurança, e será o caso das salas públicas, no interior das próprias instituições estatísticas. Nelas, projetos especiais, devidamente avaliados e aprovados, são desenvolvidos, e as agregações resultantes só são liberadas depois de vistoriadas pelas instituições estatísticas. Todo cuidado é pequeno. 
Por fim, resta a questão da concessão de informações individuais a parceiros privilegiados, parceiros que, em princípio, formam um sistema de instituições estatísticas. Havendo essa concepção sistêmica, as informações individuais já não seriam prestadas apenas a uma instituição, mas antes, a todas que formassem o referido sistema. Os riscos crescem, sem dúvida, por mais que todas as instituições estatísticas envolvidas sejam sólidas e tenham indiscutíveis deontologias. Mas, sem dúvida, não há como negar que seria uma avanço.

\section{Propondo um programa de pesquisa}

Para começo de conversa, tudo deve seguir na rigorosa garantia do sigilo, no respeito ao direito à privacidade dos informantes, e, também, garantir a máxima divulgação de informações, no respeito ao direito à informação. Dito de outra forma, as instituições estatísticas devem, igualmente, cuidar de sua credibilidade e de sua legitimidade. Isto posto, as instituições estatísticas precisam dedicar-se em avançar a questão, associando-Ihe informação e aumentando o conhecimento; e se propõe um programa de pesquisa às instituições estatísticas, não apenas a nacional, mas todas, também as estaduais e as municipais, como segue:

- Pontos de fundo (I):

a) Refletir as noções chaves de obrigação e de sigilo, ajustando-as aos tempos, pensando sua atualidade e propriedade na sociedade da informação.

b) Aprofundar e sistematizar o conhecimento das experiências de outros países (outras instituições estatísticas), seus métodos e suas práticas.

- Tempos de campo e de crítica / análise:

c) Criar condições de conquista aos informantes, estimulando e negociando a cooperação entre instituições, associações, corporações, entre outras. d) Avaliar os métodos de garantia do sigilo em todas as etapas do processo de pesquisa (técnica e tecnologia), revelando instruções operacionais.

- Tempo da divulgação / disseminação:

e) Avançar na liberação de microdados, bem assim, avançar na criação de sistemas de acesso e de análise.

f) Avançar na questão da delegação do sigilo, no contexto de sistemas de instituições estatísticas parceiras (avaliar a noção de redes de saber).

- Pontos de fundo (II):

g) Rever a legislação pertinente, ajustando-a à sociedade da informação em que vivemos; sobremodo, tirando dessa legislação o ranço autoritário.

h) Considerar a deontologia dos estaticistas, valorizando-a e reforçando-a. Instituir um debate sobre ética.

O item c, acima, é o ponto nevrálgico das mudanças. Advoga-se criatividade para vencer a situação presente, em que o entrevistador é deixado sozinho diante do entrevistado, contando somente com os recursos tradicionais de convencimento, sua simpatia, um ou outro brinde, um discurso fragilíssimo sobre a natureza das estatísticas, da qual surge o sigilo; enfim, sobre a importância da participação dos informantes, tudo isso, sem olvidar a frágil lei, com sua prescrição inaplicável de multa aos renitentes. Esse estado de coisas, além de injusto, é perigoso, porquanto implicando mais e mais recusas e/ou más respostas; e, se a situação não é ainda desesperante, deve-se à experiência dos entrevistadores, habituados a transpor ou derrubar muralhas.

Novas saídas devem surgir. Por exemplo, mirar-se na já tradicional exigência da SUDENE, que só libera recursos a projetos mediante, entre outros documentos, a apresentação de uma certidão negativa do IBGE (para empresas 
nacionais, a certidão negativa deve referir-se a todo o país); ora, por que também não o fazem os bancos oficiais, como o Banco do Brasil, a Caixa Econômica Federal, o Banco Nacional de Desenvolvimento Econômico e Social, entre outros? E, por que não exigir pronta resposta das concessionárias de serviço público, como parte dos contratos de concessão? Por que não vincular a concessão de licenças pelas prefeituras também à apresentação de certidões negativas a serem dadas pelo IBGE? E mais, numa linha de voluntária cooperação, por que não conquistar simpatias de empresas e de pessoas, através das associações de classe, como a Federação das Indústrias do Estado de São Paulo, a Federação das Indústrias do Estado do Rio de Janeiro, e similares, ou das associações profissionais, como as seções da Ordem dos Advogados do Brasil, do Conselhos Regionais de Economia, do Conselhos Regionais de

\section{REFER Ê N CIAS}

BIANCHINI, Z.M. Considerações sobre o sigilo das informações. Mercosur: Sinopsis Estadística, v.2, p.307-312, 1995.

CITTEUR, C.A.W.; WILLENBORG, L.C.R.J. Public use of microdata files: current practices at national statistical bureaus. Journal of Official Statistics, v.9, n.4, p.783-797, 1993.

DOYLE, P. et al. (Ed.). Confidentialiy, disclosure, and data access: theory and practical applications for statistical agencies. Amsterdan: Elsevier, 2001.

FEDERAL STATISTICAL, US. Report on Statistical Disclosure and Disclosure avoidance techniques. Statistical Policy Working Papers, n.2, p.58, 1978.

FEDERAL STATISTICAL, US. Report on Statistical Disclosure Limitations Methodology. Statistical Policy Working Papers, n.22, p.131, 1994.

SENRA, N.C. A questão dos registros administrativos vis-à-vis à geração de estatísticas. Revista Brasileira de Estudos de População, Campinas, v.13, n.2, p.199-205, 1996.
Contabilidade, e outros? Por que não negociar com as grandes empresas a elaboração de programas contábeis de resposta ao IBGE, para sua matriz e para suas filiais? Daí afora, fazendo com que o estar quites com as obrigações estatísticas seja compromisso das entidades instituídas e dos poderes constituídos; afinal todos delas precisam. Tudo isso num movimento de negociação em grande estilo, envolvendo os mais altos escalões das instituições estatísticas.

\section{AGRADECIMENTOS}

O autor reconhece nas observações de Nuno Duarte Bittencourt, de Paulo César de Sousa Quintslr, de Paulo de Martino Jannuzzi e de Gylcilene Ribeiro Storino, em versão preliminar deste texto, contribuições muitíssimo valiosas. Muitas foram aqui incorporadas, contudo, não se Ihes impute aceitação ao resultado.

SENRA, N.C. Garantia de sigilo, a deontologia do Estaticista: sua conduta ético-moral. Reflexão para discussão, IBGE, 1999. Disponível em: <www. biohard.com.br/ncsenra>. Acesso em: $20 \mathrm{dez}$. 2004.

SENRA, N.C. Informação estatística e política pública: desafios futuros no presente. Transinformação, Campinas, v.13, n.1, p.57-65, 2001.

SENRA, N.C. Regime e política de informação estatística. São Paulo em Perspectiva, São Paulo, v.16, n.3, p.75-85, 2002.

SENRA, N.C. O saber e o poder das estatísticas. Uma história das relações dos Estaticistas com os Estados e com as Ciências. Rio de Janeiro: IBGE. 2005. [no prelo].

SILVA, P.L.N. O sigilo das informações estatísticas: idéias para reflexão. Rio de Janeiro: IBGE, 1988. (Série Texto para discussão).

THOROGOOD, D. Statistical confidenciality at the European Level. Conference of European Statisticians, Greece, 1999. 
